\title{
Del design capitalism al capitalismo cognitivo: arte e industria, nuevos lazos, inuevas tensiones?*
}

\author{
Yann Moulier Boutang \\ Traducción del francés al español de Luis Alfonso Paláu-Castaño \\ Universidad Nacional de Colombia, Medellín, Colombia \\ lapalau@gmail.com
}

\section{Argumento}

El paradigma artístico (y académico) toma una importancia creciente en la producción de bienes, servicios y conocimientos. ¿Cuál es el origen de este fenómeno? ¿Se trata de una simple moda? ¿Se trata de un recurso al arte decorativo romántico, o bien, como en los bellos días del Segundo Imperio, de otro rostro de la industrialización, que conjugó (en reacción contra el decorado "antiguo") funcionalidad, estética y gusto de un público que se captaba a sí mismo de acá en adelante como tal? ¿Se trata de una variedad de industrialización, la de un dominio de la cultura que había escapado hasta el presente de la mercantilización, gracias a las tecnologías de lo digital? ¿De una industrialización que dejaría intactos sus principales parámetros?

A nuestra manera de ver, la relación es mucho más radical y profunda. Traduce una nueva gran transformación. El design capitalism implica al prosumidor (productor + consumidor) en la individualización del objeto. La creatividad es requerida de parte de los diferentes agentes en las diferentes etapas de la producción (concepción, dominio de la cualidad, prosecución de los productos, consumo inteligente). La ciudad por proyectos descrita por Éve Chiapello y Luc Boltanski (2002) reforma todas las categorías: el trabajo, el valor, la división del trabajo, la organización, la relación forma y fondo, forma y función. Pero no se trata solamente de una justificación nueva de la industria donde lo procedimental habermasiano serviría de nuevo elemento decorativo de las funcionalidades $\sin$ cambios. Nuevas perspectivas y nuevas tensiones encuentran acá su origen.

Se partirá de una constatación: el arte y el conocimiento constituyen de acá en adelante atractores del mundo industrial. Se examinará luego las razones de esta transformación. La razón principal tiene que ver con que el arte juega

Cómo citar: Moulier Boutang, Y. (2020). Del design capitalism al capitalismo cognitivo: arte e industria, nuevos lazos, ¿nuevas tensiones? Ciencias Sociales y Educación, 9(17), 339-349. https://doi.org/10.22395/csye.v9n17a16 Traducción realizada por Luis Alfonso Paláu-Castaño. Agradecemos la editorial Fayard por permitir el acceso del libro en francés para su versión, en partes, en español. Se conserva la versión editorial en francés. Nota del editor. Recibido: 10 de febrero de 2020.

Aprobado: 16 de marzo de 2020. 
el papel de una verdadera matriz de lo que yo llamo el advenimiento del capitalismo cognitivo (Moulier, Corsani y Lazzarato, 2004), y de una verdadera mutación de la naturaleza misma de lo industrial gracias a lo digital y a la técnica en los dominios tan variados como la división del trabajo, la retribución, la valorización de los intangibles y de las redes. Esta transformación es a mi sentir tan importante que tengo la tendencia a acentuar esta discontinuidad evitando para ello emplear la palabra industrial. Es en este marco global que conviene examinar las nuevas contradicciones que sacuden lo que Bernard Stiegler llama lo hiperindustrial.

\section{El arte y el conocimiento, atractores del mundo industrial. La creatividad y la inventividad son las nuevas reglas}

La constatación: la incorporación de la producción de conocimiento nuevo juega un papel cada vez más importante en la producción a secas. El fenómeno no es en sí nuevo. El conocimiento científico hace cuerpo con la emergencia de la técnica y de la transformación del mundo, cuya hija directa es la revolución industrial. Lo que cambia es la amplitud que reviste el fenómeno. El arte, igualmente, no ha estado de más. El mundo de la metalurgia, de la Torre Eiffel, es también el del palacio del descubrimiento y de sus imponentes frontones neoclásicos. Lo que es nuevo, la verdadera modernidad que lo posmoderno no ha aminorado, es que el arte se ha vuelto, no el atuendo de lo industrial, sino su centro de gravedad. Dicho de otro modo: el capitalismo industrial había aceptado el design como conciliando el fondo - la repetición de lo idéntico que permite beneficiarse de las economías de escala - o la función —el valor de uso- con la forma artística o decorativa -esto corresponde en música al motivo o leitmotiv-. Se asiste en apariencia a una inversión (anunciada y performada por el arte contemporáneo); la forma industrial se vuelve el fondo(s) del arte en el sentido de los dos homónimos: sustrato o sustancia, y fondos de comercio.

Ya sea para mantenerlo a distancia en una crítica del mundo de los objetos o, al contrario, para eliminar las escorias decorativas que visten y parasitan la percepción de la función pura - movimiento que se prosigue hasta el cuestionamiento de la representación-, el mundo industrial se vuelve la materia prima y la naturaleza naturada, el mundo común de donde el arte saca sus motivos, así como sus objetos de efectuación. El borde entre el arte y la vida cotidiana se vuelve un objeto de cuestionamiento irónico y el estudio de la cultura recusa las particiones tradicionales entre las escalas de lo grande y de lo pequeño, de la élite y de la masa. Ciertamente, el arte se populariza, se democratiza — "Everyone is an artist"-, y como la religión, conoce una laicización y una crisis del carácter de "aparte" de sus artistas. Toda una vertiente de la crítica salida de la Escuela de Fráncfort percibe aquí simplemente una degradación, una decadencia 
(incluso si la palabra nunca se emplea, remite en demasía a la desacreditada filosofía de Toynbee; es claramente este contenido el que se transparenta en los análisis de matriz heideggeriana, los de la homogenización y de la banalización del "se" y del "mundano"). Pero esta "trivialización" se acompaña al mismo tiempo de un movimiento de secularización y de diseminación de lo artístico (de lo sagrado y de lo religioso) en la vida cotidiana. Una resacralización pagana de los entes acompaña una pérdida de estatuto del ens summum monoteísta o de la muerte de los dioses. Lo divino como el eros se difunde por la superficie de las cosas (como los kami japoneses). En este cuadro, el lugar del humano terrestre (ya sea pensado como imagen de Dios o el Dios antropomorfo) es el objeto de una revaluación radical y, en primer lugar, de un violento descentramiento. El hombre ya no está en el centro, destronó al valor supremo, pero como valor supremo, él a su vez ha sido tragado de nuevo a una parte de la biosfera animal y de la vida en el universo (con la posibilidad creciente de que exoplanetas puedan abrigar otros vivientes).

Poshumano en tanto que ya no está hecho a la imagen del ens summum ni es la creatura más importante; sin embargo, no por ello el hombre cae al estatuto animal o de simple viviente. Regresa con la dominación creciente del viviente muy próximo de Prometeo, un cíborg productor de la procreación, de su cuerpo, de los "instintos", de su género, de la performance física e intelectual asistida por computador y diferentes prótesis bioquímicas. La creatividad reclamada en los manuales de gestión de los recursos humanos se adosa a una generalización de la creación, de una creación inmanente que recurre a modelos autopoiéticos y a los fenómenos de autoorganización (como en la construcción enáctica de la percepción) mucho más que en los modelos trascendentes. Los imperativos de autonomía y de producción de sí mismo (de la moral a la gestión del capital humano, al emprendimiento de la toma de riesgos) no son solamente "valores" de justificación, sino una ideología sorprendentemente funcional en la disolución de las resistencias de los cuerpos sociales en una recombinatoria fluida permanente.

Cualesquiera sean las raíces profundas del imperativo de creatividad, en el dominio de los recursos humanos, el doble imperativo contradictorio: "Sed creativos y vendedores" se vuelve: "Sed vendedores porque sois creativos"; lo que conduce a cuestionar la distinción y la jerarquía entre los ingenieros y los comerciales. Ciertamente, se puede tratar este nuevo imperativo como un simple eslogan publicitario que disimula, tras un efecto de moda, una carencia sustancial de originalidad. La empresa Renault hace bien en exhibirse como "creadora de automóviles", y tomarle prestado más a los ritos de la alta costura que a los de la metalurgia, dado que las condiciones de trabajo que prevalecen en el tecnocentro de Guyancourt, su Departamento de Investigación y Desarrollo, pertenecen claramente al mundo industrial del tiempo taylorizado al extremo. 
La back door (la entrada de servicio) industrial permanece tras espacios de recepción que se parecen cada vez más a museos o a hoteles de lujo.

Este artificio decorativo, sin embargo, no le quita nada al hecho masivo de que las empresas se presentan de ahora en adelante como creadoras de un mundo de emociones, de experiencia, de medio de vida (Rifkin, 2000; Lazzarato, 2002), en suma, de una nueva estética (en el sentido primario que tiene esta palabra: experimentar emociones, ser afectado). Lo que la publicidad había soñado o adelantado, la nueva edad industrial (posindustrial o hiperindustrial) lo ha hecho. Más allá de la esfera del marketing, el deslizamiento o "giro artístico" toca también la evaluación de los recursos humanos del lado de las direcciones, pero de la parte del asalariado o "proveedor" de servicios (cuando está instalado por su cuenta) que debe interiorizar una nueva concepción de su "valor". Lo que se pone en primer plano de ahora en adelante es la competencia y la empleabilidad, opuestas al empleo y a la calificación técnica o a la cotización por puesto. No es tanto la individualización del puesto de trabajo el que prevalecería, sino la imposibilidad de apreciar el poder de aprendizaje, de responder con soluciones adaptadas a contextos nuevos por fuera de situaciones cada vez singulares. La regla general (la ley) no cede solamente al contrato, como tantos juristas lo han notado, sino a la singularización artística por la cual todo es caso particular. Que esta normatividad, más próxima del juicio estético de la tercera crítica de Kant que de la máxima moral (ética o política) o de las categorías de la razón científica, se revele como una temible máquina para deconstruir los compromisos sociales, es una evidencia, pero esta realidad se impone cada vez más crudamente.

Una última anotación preliminar: lo artístico se descubre como una modalidad de lo cognitivo a partir del momento en que no se reduce el conocimiento a los conocimientos codificados y simplificados, y que es lo complejo aquello de lo que se quiere dar cuenta. El arte es entonces una modalidad privilegiada de acceso a lo complejo. ¿Cuáles son las razones de este nuevo curso "artístico" y "estético" del mundo industrial?

\section{Las razones de la mutación}

La lógica profunda del nuevo curso cognitivo y artístico del capitalismo tiene que ver con los siguientes factores: la presión de la competencia mundial ante todo; ella obliga a las empresas y a las naciones a diferenciarse por la innovación permanente, lo que entraña un recorte espectacular del ciclo del producto. Las economías de escala están entonces relegadas a un segundo plano, pues las series son demasiado cortas. Las economías de aprendizaje se vuelven la clave de una adaptación rápida tanto del productor como del consumidor. 
Las empresas remontan río arriba o río abajo del momento de la fabricación para explorar en los segmentos más portadores de valor añadido, por tanto, hacia los inmateriales. En esos inmateriales distinguimos los inmateriales 1 y 2, como lo vamos a ver a continuación.

La integración de la comercialización, así como de la relación cliente adelante, y la incorporación atrás del máximo de conocimientos y de innovaciones, se traducen en una globalización de la actuación económica. La competitividad por fuera del costo remite a los intangibles o inmateriales, es decir, a la cualidad total, a la organización, a las redes de proveedores, usuarios, así como de los factores aún más inestables como la confianza, al capital humano o intelectual y, para terminar, a la cualidad de los equipamientos públicos y del entorno. Es la sociedad, por no decir la producción de la sociedad, la que se convierte en el terreno de enfrentamientos entre naciones (Reich, 1997).

La tarea de las empresas consiste en integrar en sus productos y sus servicios el máximo de las externalidades positivas que provienen de los equipamientos, de los territorios productivos. Se ve que estamos lejos de los simples hábitos nuevos del buen viejo capitalismo industrial y de las simples entradas de preludio a una mercantilización del mundo.

Digamos aquí una palabra sobre el concepto de inmaterial y de su papel cada vez más importante. Para el economista ortodoxo, lo inmaterial es lo potencialmente codificable bajo derechos de propiedad, cuando la innovación sea reconocida por el mercado como activo susceptible de generar ingresos. Pensamos, por nuestra parte, que lo inmaterial reintegra en el cálculo económico las externalidades cuyo peso va siendo mayor a medida que las interacciones mercantiles y no mercantiles se multiplican en mundos complejos. Esta irrupción de las externalidades se declina en diferentes dominios: para el goodwill del contador, se trata de la distancia positiva entre el valor constatado en el momento de las adquisiciones y el valor de los fundamentales in the books (en la contabilidad). Para el financista que debe autorizar créditos, es la distancia entre el concepto de beneficio contable y el concepto de valor potencial que envuelve al primero y autoriza las transformaciones dinámicas de las empresas. En el marketing es el valor de la marca verdadero ADN de la empresa (Moulier y Rébiscoul, 2006).

Es necesario subrayar igualmente que lo inmaterial (lo intangible de los contadores) se lamina en dos tipos de recursos que revelan cada vez mejor las nuevas tecnologías de la información y de la comunicación: inmaterial 1 e inmaterial 2.

Por inmaterial de nivel 1 o inmaterial 1 se entenderá un proceso de incorporación de lo cognitivo y de los saberes en la producción material acompañada de 
la emisión de derechos de propiedad sobre soportes codificados (patentes, derechos de autor y marcas). Por inmaterial de nivel 2 o inmaterial 2 se entenderá aquello que rodea al inmaterial 1, su halo, que es la clave de un proceso más delicado y más complejo de subordinación de la producción material con dispositivos de captación de innovación. La gobernanza económica clásica está perturbada por la consideración de esos inmateriales implícitos como la audiencia, la opinión pública, la confianza capitalizada en las marcas. Las NTCI permiten una codificación creciente de los inmateriales 1 (en particular los procedimientos repetibles y por tanto industrializables), pero la producción de los saberes que permiten hacer aquello que no se sabía hacer (la innovación) implica la captación de los inmateriales 2, y la informatización hace aparecer su irreductibilidad y su valor creciente.

La digitalización —así como antaño en el curso de los dos siglos precedentes, la mecanización - incorpora los inmateriales que pueden ser codificados en los datos y los procesos bajo forma de programa (logiciales). Haciendo esto los industrializa, los serializa, pero hace que caiga su costo marginal en función de la progresión exponencial de las capacidades de memoria, de copia, de encaminamiento y de tratamiento. Lo que revela lo digital y la tontería tenaz de los computadores, es la inteligencia desnuda, pura, como capacidad de aportar respuestas nuevas a cuestiones no previstas, y no soluciones que no habían sido preprogramadas. Es pues la inteligencia y la producción de conocimiento de nivel 2 , las que sirven para hacer y para designar/diseñar cosas que no se sabía hacer.

\section{El arte, matriz del capitalismo cognitivo}

Volvamos pues hacia el nuevo "curso artístico" que está en vías de operarse en la mutación del capitalismo, y que nos es tanto más necesario tomar en serio como la revolución de las nanotecnologías y de los objetos inteligentes, así solo esté en sus balbuceos, lo que va a ampliar de forma exponencial las posibilidades de interacción entre los agentes, entre los agentes y los objetos, pero también directamente entre los objetos ellos mismos. El arte es un medio de producir atención y sentido en una sociedad de la información y del ruido. Esto existía ya en la sociedad industrial. La prescripción artística producida por el design como medio de producir innovación en una economía global igualmente existía. Simplemente, lo que solo era un fenómeno de vanguardia se masificó. El amateur juega un papel crucial en la formación del público, de la audiencia; el usuario conocedor (prosumidor) coproduce hoy los programas al reducir el número de bugs, si tenemos que el código fuente es accesible como es el caso en los software libres. 
Pero es en la constitución de los dispositivos de revelación y de captura de inmateriales 2, particularmente en las prácticas de red de utilizadores, donde el arte contemporáneo se revela portador de una experiencia, de un saber que las empresas se ponen a observar en su centro de investigación y desarrollo. Es en su capacidad de engendrar inmateriales del nivel 2 donde se mide de acá en adelante su facultad para retener el capital intelectual.

Si examinamos las características de la producción flexible que Robert Reich había caracterizado como la "manipulación de imágenes, de símbolos y del lenguaje", y a la que conviene añadir el papel creciente de las ciencias cognitivas que intervienen en la producción de lo percibido, de lo sensible (con el paradigma de la enacción desarrollado en la UTC de Compiègne ${ }^{1}$ ), vemos que es en la frontera entre lo explícito y lo implícito (inmaterial 1 y 2), entre lo mercante y lo no mercante (externalidades), donde se juega la innovación. Por ejemplo, la externalización (outsourcing) de los procesos productivos, de los que Jeremy Rifkin analizó su nacimiento precoz en los estudios de Hollywood, y la extensión a partir de los años 1980 al conjunto de la producción industrial, reviste de ahora en adelante la forma del crowdsourcing. Se encuentran inventariados en esta última técnica, gracias a la herramienta de la red informática de internet, y haciendo llamado a la cooperación del público, los recursos disponibles del territorio cognitivo por fuera de los límites de la empresa para resolver problemas de sobrevivencia. (Ver el ejemplo de la compañía minera canadiense Goldore para evaluar correctamente sus reservas en mineral aurífero, dado por Tapscott y William (2007)).

Se instala un nuevo paradigma de la actividad humana. No se trata ya de producir un output de valor mercantil máximo a partir de inputs racionados en una economía dominada por la escasez, según un modelo mecánico de gasto de energía (siguiendo el modelo canónico de la maximización bajo constreñimiento de minimización de los costos). La eficacia consiste en obtener un outcome (resultado global) en un medio complejo donde los recursos son abundantes y donde es la preservación de la biodiversidad la que permite su reproducción, su transformación, su dinámica y, por qué no, su rendimiento.

Empleamos la metáfora de la polinización de las abejas para caracterizar la mutación del concepto de actividad productiva. Tanto la utilidad como el precio económico de las abejas tiene mucho más que ver con la polinización de las plantas, y particularmente de las frutas y de las legumbres, que con su producción de miel (la relación es de trescientos cincuenta veces a una). Las implicaciones de esta transformación sobre la convención de empleo son

Ver los trabajos realizados en el seno del Costech en la UTC, y desarrollados por Charles Lenay, Olivier Gapenne y John Stewart. 
particularmente visibles en el régimen de garantía de ingresos de los intermitentes del espectáculo en Francia en momentos de la encuesta nacional efectuada en 2003-2005 (Corsani y Lazzarato, 2008) bajo nuestra dirección.

En una economía dominada por la red, el modelo de la contribución ya no es el del intercambio mercantil o no, mientras que la eficacia del mercado, por un lado, y la de la jerarquía vertical (el Estado y la empresa), por el otro, son cuestionados como modelo organizacional único e indiscutible (Benkler, 2007). Numerosas combinaciones productivas practicadas desde hace tiempo en el modelo académico o artístico eran consideradas por la corriente dominante de la economía con una mezcla de desprecio y de conmiseración reservada a la marginalidad. Ahora son adoptadas por la industria "dura", pues uno se da cuenta que esos métodos corresponden a sistemas complejos que incorporan fácilmente las externalidades positivas, que economizan energías de efecto invernadero, que disminuyen los costos de transacción y, last but not least, permiten rendimientos incomparablemente mejores.

Si lo que más vale hoy, en el plano económico, es el poder de diferenciación, de innovación, es por la interactividad de múltiples agentes y la densidad de la polinización en medios vivientes complejos que se obtiene lo mejor. Las cuestiones de organización de medida de la creatividad, del tiempo de cerebros disponible, la forma empleo y la forma empresa, se vuelven otros tantos desafíos.

El sociólogo estadounidense Richard Florida (2007) y el economista Eric von Hippel (2005) del MIT (que cuestionan fuertemente la estructuración vertical), subrayan que los sistemas productivos innovadores son los que están organizados en rizoma, constituyendo redes que se acodan hasta el infinito (como en la acodadura vegetal), que son ascendentes (bottom up), y no descendentes (top down). El valor de la cooperación puede ser aprehendido en la producción y la constitución a través de las redes de opinión común (de consumidores, de accionistas, de ciudadanos, de los humanos miembros de la biosfera, etc.). Las estrategias de marketing y de financiación no constituyen los modelos sobre los cuales vendría a alinearse las formas nuevas de producción. Son ellas, por el contrario, las que imitan esos movimientos de la sociedad.

\section{Nuevas tensiones}

Sería falso representarse el giro "artístico" del capitalismo contemporáneo como una simple caminada que proseguiría con otros medios los procesos racionalizadores del mundo industrial. Como siempre, bajo el capitalismo en sus tres avatares históricos, nuevas tensiones aparecen que desequilibran por adelantado el sistema. 
La primera tensión, de orden ecológico, aparece de manera más o menos escandalosa. La omnipotencia de la técnica que se acerca al dominio de la producción del viviente (incluido aquí el viviente humanoide) coincide con la puesta en evidencia del carácter no necesariamente positivo de la acción y del crecimiento en lo tocante a los límites materiales globales (las posibilidades de la biosfera). Peor aún, con el principio de precaución, aparece en el mundo de la técnica y de la ciencia algo profundamente ajeno a la racionalidad del Renacimiento, y reprimido en los dominios del arte y de la religión. La idea de que el conocimiento, en lugar de desembocar necesariamente en la acción y la transformación de la res extensa cartesiana en una dinámica lineal del progreso, incita a abstenerse de actuar o a desplazar el campo de realización de actualización de la humanidad hacia valores de desarrollo extraeconómico y, por qué no, antieconómico. Se trata de actuar en la difícil reconciliación, ya no de la cabeza bien llena con una cabeza bien hecha, sino de la prosperidad material de los seis y bien pronto nueve mil millones de humanos, considerada posible de llevarse a cabo por medio del crecimiento, con la sobrevivencia de las condiciones de vida en el planeta. La primera década del siglo XXI ha visto una recuperación de la aceleración de la historia; la "oscilación del mundo" (Michel Beaud) no es una simple extensión del mundo industrial y del mercado a los dos mil millones de individuos suplementarios (la China y la India esencialmente); ella destruye una a una las seguridades engañosas en materia de crecimiento, de viabilidad de las tendencias actuales, con una velocidad impresionante. El regreso de lo reprimido por el crecimiento y el optimismo industrial se superponen al "nuevo giro artístico" del capitalismo. Sería ridículo en estas condiciones ver en él solamente una jugarreta de más del capitalismo para perpetuarse. El giro artístico es portador de una desestima fuerte de los intereses cortoplacistas de la regla del provecho. Ciertamente, el capitalismo cognitivo está llevado a añadir el arte a su arco y hacer de él un dispositivo de captación de las externalidades positivas de la sociedad polen. Pero semejante sujeción no deja de introducir riesgos de rebote; la globalización espacial o temporal (la extensión de la perspectiva de la suerte de las generaciones futuras en la ética del desarrollo sostenible) hace aparecer los desequilibrios y requiere de manera más o menos imperativa que las externalidades negativas sean saldadas (por el impuesto o por mercados de los derechos a contaminar).

Una segunda tensión que surge en el corazón mismo de la economía de mercado, que parece ya no tener modelo rival después de la caída del socialismo real, tiene que ver con la transformación en el contenido y la forma del valor que introduce el paso a una sociedad de la información. Los conocimientos implícitos no son reductibles a la pura información y mucho menos a mercancías. Algunos francamente no tienen precio, en el doble sentido de esta palabra (son las condiciones de posibilidad de todo precio o mercado y, 
por tanto, están por fuera del mercado). A tal punto son preciosos que está excluido el poder asignarles un precio.

¿Qué valen la cultura, el arte, ese tipo particular de conocimiento? No dejan de tener costo, pero muy a menudo no tienen precio. Arte y conocimientos presentan las características de los bienes cuasi públicos (Aigrain, 2005). Su puesta en el mercado afronta tres dificultades:

1. La apropiación privativa no puede sino resultar de convenciones jurídicas y no deriva ni de la naturaleza del objeto (divisible, excluible, no rival) ni del funcionamiento "natural" del mercado (ver la inestabilidad de un mercado del arte).

2. El modelo de lo gratuito de una parte de los segmentos de fabricación progresa muy rápido puesto que es sobre lo esencial del valor añadido antes y después que se concentra el retorno sobre la inversión posible.

3. Lo digital y la potencia de almacenamiento, de copia, de encaminamiento y de tratamiento de la información, hacen que vacilen las barreras técnicas que se oponen a la transgresión de los derechos de propiedad intelectual.

Recojamos algunas conclusiones provisionales para alimentar el debate en torno de los nuevos mundos industriales (y el plural no está de más). El arte y la cultura de masas no podría ser visto simplemente como instrumentos de control y de mercadeo en la era de la tercera mundialización, a la manera como lo hace la Escuela de Fráncfort.

El arte expresa y revela la contradicción muy fuerte existente en el capitalismo cognitivo entre la cooperación de los cerebros en red (la inteligencia colectiva) como condición misma de la innovación y de la producción de conocimientos nuevos; por tanto, del valor económico por una parte, y de las estructuras de apropiación de la actividad humana en su dimensión polinizadora, de la otra.

\section{Referencias}

Aigrain, P. (2005). Cause commune. L'information entre bien commun et propiété. Fayard.

Benkler, Y. (2007). The Wealth of Networks. How Social Production Transforms Markets and Freedom. Yale University Press.

Chiapello, É. y Boltanski, L. (2002). El Nuevo espíritu del capitalismo. Akal.

Corsani, A. y Lazzarato, M. (2008). Intermittents et précaires. Editions Amsterdam.

Florida, R. (2007). The Flight of the Creative Class. The New Global Competition for Talent. Harper Collins.

Lazzarato, M. (2002). Puissances de l'invention: La Psychologie économique de Gabriel Tarde contre l'économie politique. Les empêcheurs de penser en rond/Seuil. 
Moulier, Y. (2008). Du design capitalism au capitalisme cognitif: art et industrie, nouveaux liens, nouvelles tensions? En B. Stiegler (dir.). Le "design» de nos existences: à l'époque de l'innovation ascendante (pp. 20-42). Fayard.

Moulier, Y., Corsani, A. y Lazzarato, M. (2004). Capitalismo cognitivo, propiedad intelectual y creación colectiva. Traficantes de sueños. https://www.traficantes.net/sites/default/files/pdfs/Capitalismo\%20 cognitivo-TdS.pdf

Moulier, Y. y Rébiscoul, A. (2006, 22 de diciembre). Qu'est ce que l'immatériel. Conferencia, París, Francia.

Reich, R. (1997). L'économie mondialisee. Dunod.

Rifkin, J. (2000). La época del acceso: la verdad sobre la nueva economía. Paidós.

Tapscott, D. y William, A. (2007). Wikinomics, How mass collaboration changes everything. Portofoglio.

Von Hippel, E. (2005). Democratizing Innovation. The MIT Press. https://web.mit.edu/evhippel/www/ books/DI/DemocInn.pdf 